\title{
Modelos mentales al interrelacionar los conceptos de célula y ecosistema, utilizando a los insectos como eje transversal
}

\author{
Mental models to interrelation with ecosystem and cells concepts, using insects as \\ transverse axis
}

Lucila Medina de Rivas, Bladimir Vera Marín, Gustavo Adolfo Bonilla Pérez y

Liliana Patricia Munares Vélez

Universidad de Antioquia. Facultad de Educación. lucilad@une.net.co, bladoo385@hormail.com,

tavobon@yahoo.com, lilianamunaresv@msn.com

\section{Resumen}

El trabajo presenta una investigación cualitativa, estudio de casos comparativo, descriptiva con observación participativa, realizada en la Institución Educativa Héctor Abad Gómez, con 14 estudiantes de grado sexto. El marco teórico se enmarca en la teoría de los modelos mentales de Johnson-Laird. La investigación fue desarrollada en cuatro fases:

1. Fase: Indagación de ideas previas sobre célula, ecosistema, insectos y otra sobre la interrelación de los conceptos

2. Fase: Introducción de nuevos conocimientos

3. Fase: Prueba síntesis, la cual permite observar el progreso de las representaciones mentales

4. Fase: Prueba de aplicación, práctica de laboratorio con un coleóptero y un ortóptero

Los resultados muestran que los estudiantes presentaron modelos innatos, económicos, finitos y de identidad estructural. Los insectos son un material potencialmente significativo, porque permitieron adquirir un progreso conceptual en los estudiantes.

En condusión, los insectos permiten desarrollar actividades llamativas y divertidas, facilitando la interrelación entre temáticas, el diálogo entre diferentes disciplinas del saber y fundamentalmente, acercándonos aún más a un conocimiento significativo.

\section{Palabras claves}

Célula, ecosistema, insectos, representaciones mentales, interrelación

\section{Abstract}

The work presents a qualitative investigation, comparative and descriptive cases study with participative observation, made in Héctor Abad Gómez Institution, with fourteen students of sixth grade. The theoretical framework is based in mental models Johnson-Laird theory. The investigation was developed in the follow four phases:

1. Phase. Questions about previous ideas refer to cell, ecosystem, insects and its interrelationship.

2. Phase. Introduction of new knowledge.

3. Phase. Synthesis test, shows the progress of mental representations.

4. Phase. Application test, laboratory practice with a Coleoptera and a Orthoptera.

The results show that students presented models innate, economics, finites with structural identity. The Insects are a potentially significant material, because Its allowed to get a conceptual progress in the students before mentioned. 
In condusion, the insects permits to develop striking and fun activities, facilitating the interrelation between thematic, the dialogue between differents knowledge disaplines and fundamentally, getting a significant knowledge.

Keyewords

Cel, ecosystems, insects, mental representation, interrelation.

\section{Introducción}

"Los insectos ofrecen una amplia gama de oportunidades de enseñanza para estudiantes preuniversitarios" (Matthews R, Flage L y Matthews J, 1997), estos nos pueden ayudar a relacionar algunos temas 0 saberes espeáficos, ya que sin lugar a dudas, los podemos localizar en muchas partes de nuestra casa o jardín siendo especies importantes en el equilibrio del ecosistema. De igual forma, son seres vivos cotidianos que están en nuestro alcance aunque a veces se presenten fobias contra estos. Por lo tanto, se pueden aprovechar para estudios que alcancen una conexión entre ciencia y sociedad, la cual es importante para el aprendizaje significativo de los estudiantes.

En relación a lo expresado anteriormente, los procesos de enseñanza y aprendizaje de las Ciencias Naturales y de la Educación Ambiental, deben estar fundamentados en la vida real/cotidiana; con el único objetivo de hacer del proceso educativo algo más creativo, nuevo e interesante de resultados satisfactorios, teniendo como pilares la construcción de conocimientos científicos a partir del análisis, la reflexión, la interpretación y la investigación con el fin de iniciar un cambio significativo en la simple transmisión de conocimientos que en nada ayudan a una formación íntegra del estudiante.

Se desea por lo tanto, romper con el velo de la pasividad en cuanto al desarrollo de una cultura cientíica; y que se trate más bien de buscar, formar, descubrir y estudiar los infinitos interrogantes que se poseen de la naturaleza. La mejor manera para alcanzar lo anterior, es comprendiendo la interrelación e interdependencia que existe entre las ciencias, la tecnología, la sociedad y la educación. De acuerdo a lo anterior, la presente investigación busca en los insectos un medio de trabajo por el cual se logre explicar los conceptos de célula -a nivel estructural y funcional- y ecosistema, teniendo en cuenta a los insectos a manera de herramientas o estrategias de estudio, con el objetivo que sean utilizados como materiales reales, de vivencia cotidiana y palpables dentro de nuestra realidad. A partir de lo anteriormente planteado en el esbozo, se trata de buscar una interdisciplinariedad de las unidades que se enseñan en el grado sexto durante un semestre escolar (célula y ecosistemas).

Para ello, se retoma a Johnson-Laird $(1983,1990,1993)$ y su teoría sobre Modelos Mentales y a Greca y Moreira (1997) quienes plantean en sus trabajos que "las personas construyen modelos mentales, análogos estructurales del mundo, frente a una determinada situación, los modelos que son elegidos para interpretarla, así como las relaciones percibidas 0 imaginadas entre ellos, determinan una representación interna que actúa como sustituto de esa situación' (Greca y Moreira, 1997), permitiendo comprender, analizar e interpretar fenómenos que ocurren en el mundo de la vida, para de acuerdo a esto, actuar y tomar decisiones pertinentes.

La base principal para la construcción de un modelo mental es la percepción y su compromiso de funcionalidad para el sujeto que lo construye. Por otro lado, de aquerdo con Moreira et al. (2002).

Los modelos mentales son representaciones que las personas construyen, idiosincrásicamente, para representar sistemas físicos (o estados de cosas más abstractos). Éstos no necesitan ser técnicamente precisos ( $y$ en general no lo son), pero deben ser funcionales. Ellos evolucionan 
naturalmente. Interactuando con el sistema, la persona continuamente modifica su modelo mental, revisando recursivamente esa construcción, hasta alcanzar una funcionalidad que la satisfaga. Obviamente, los modelos mentales de un individuo son limitados por factores tales como su conocimiento y su experiencia previa con sistemas semejantes, así como por la propia estructura del sistema de procesamiento de información del ser humano (Norman, op. cit. p. 8).

De acuerdo con lo anterior, las representaciones mentales que provienen del conocimiento cotidiano son únicas, por lo aual cada alumno percibe de manera única lo que se le enseña. De igual forma, el profesor enseña el fruto de sus representaciones. Consecuentemente, en los procesos de enseñanza y aprendizaje, se utiliza un modelo conceptual cuando el profesor enseña, la idea básica es que " $e l$ modelo conceptual es un instrumento de enseñanza, pero el instrumento de aprendizaje es el modelo mental" (Moreira, 1997) de forma tal que para aprender el modelo conceptual el estudiante hace uso de modelos mentales. Pero muchas veces los estudiantes no recurren a la realización de un modelo mental, además "no construyen modelos mentales para interpretar las proposiciones que conformen el modelo conceptual $y$ mucho menos representaciones mentales más potentes que las artiaulen y que correspondan a los modelos conceptuales subyacentes" (Moreira, 1997), lo que evidencia dificultad para construir modelos y lo que conlleva a los estudiantes hacia un aprendizaje mecánico o memorístico por ejemplo; al tratar de dar respuesta a un problema, aspiran encontrar una fórmula que resuelva dicho problema.

Un modelo mental nunca es completo, sino que a medida que el sujeto descubre nueva información y adquiere nuevos conocimientos, este es ampliado y posiblemente se acerque más a un modelo conceptual. Por lo tanto y de acuerdo con Moreira (1997) cuando se habla de representaciones se hace referencia al conjunto de símbolos que nos permite representar algo, ya sea del mundo interior o exterior, y una representación mental es interna y puede ser analógica 0 proposicional.

Cuando se habla de representación analógica se hace alusión a imágenes visuales, auditivas o táctiles. "Las imágenes son representaciones mentales concretas, formas de ver las cosas, los fenómenos, a las que se reaurre para recuperar y captar la esencia de las mismas, auanto menos, los detalles que han resultado relevantes al individuo que las construyd" (Moreira, 1998). Y al hablar de representaciones proposicionales se hace referencia al lenguaje de la mente que se da de forma inconsciente, no son frases en cierto idioma (Ibídem). Por lo tanto, las representaciones mentales son una especie de código que maneja nuestra mente, este tipo de representaciones son individuales pues se dan en la mente de cada individuo; organizadas ya que nuestra mente crea ciertos patrones o reglas y abstractas debido a que una de estas proposiciones puede abarcar más de una.

Ahora, retomando la perspectiva de Johnson - Laird, existen tres tipos de representaciones: La primera se refiere a la representación proposicional "son cadenas de símbolos que corresponden al lenguaje natural", la segunda; son los modelos mentales quienes "son análogos estructurales del mundo" y el tercer tipo de representación son las imágenes, "como aquellas perspectivas de un modelo mental", los anteriores tipos de representaciones mentales, son necesarias para lograr explicar las diferentes formas en que las personas razonan, realizan inferencias y comprenden aquello que los rodea, además diferenciándose cada una por su estructura y funcionalidad.

En consecuencia, por mayor rigor que haya, en la ciencia no se alcanza nunca el conocimiento verdadero en el sentido que se reproduzca exactamente del mundo real, sino que tenemos "modelos crecientemente más complejos y potentes para predecir, explicar y simular la estructura del mundd" (Pozo y Gómez, 1998) y en las Ciencias Naturales (además de todas las ciencias) todos los modelos han ayudado a explicar aquellos fenómenos naturales que están enmarcados en el mundo de la vida, y por ende la ciencia. 


\section{Desarrollo}

\section{Fase Uno}

En primer momento, se reunirán a los participantes en equipos (3 personas) y se les preguntará sobre las relaciones existentes entre las células y los ecosistema, además se discutirá sobre las características estructurales y funcionalidades de las células en los insectos, con el fin de que puedan desarrollar su nicho ecológico dentro del ecosistema.

\section{Fase Dos}

Se desarrollará y se expondrá unos pequeños auestionamientos sobre las relaciones establecidas entre las células y los ecosistemas, además se les presentará fotografías de imágenes de células de dos órdenes de insectos diferentes (coleóptero y ortóptero) de algunas de sus extremidades (alas y patas). Se pedirá la esquematización de lo observado y la descripción de acuerdo a la relación existente entre la forma de la célula o en su defecto de la morfología del insecto, y el papel que puede cumplir éstas en el ecosistema.

\section{Fase Tres}

Al final se socializará el trabajo entre los participantes y se discutirán sus apreciaciones de acuerdo a los principios de los modelos mentales desde la teoría de Johnson-Laird.

\section{Bibliografía}

Greca, I. M; Moreira, M A. 1997. Modelos Mentales, Modelos Conceptuales y Modelización. Instituto de Física, UFRGS. Porto Alegre RS. Pág. 107.

Johnson-Laird, P. (1990). El Ordenador y la Mente. Introducción a la Ciencia Cognitiva. Cognición y desarrollo humana. Ed. Paidós. Barcelona.

Martinez M. M. 1996. La Investigación Cualitativa Etnográfica en Educación: Manual Teórico Práctica. Bogotá. Círaulo de Lectores.

Matthews R., Flage L. Y Matthews J. 1997. Insects as teaching tools in primary and secundary education. Joumal Review of entomology. Vol. 42. Pág. 269-289.

Pozo, J. I; Gómez, M. A. 1998. Aprender a Enseñar Ciencias. Madrid. Ediciones Morata. 